\title{
Multi Objective Optimization of Forging Process of Arc Aluminum Alloy Forgings Based on Response Surface Methodology
}

\author{
Fan Lidan ${ }^{1, a}$ and Peng Shuming ${ }^{1}$ \\ ${ }^{1}$ Jilin Engineering Normal University, Changchun, China \\ a574024123@qq.com
}

Keywords: Large-Scale Arc-Shaped forging; Multi-Objective optimization strategy; Response surface method; Process parameters

\begin{abstract}
In order to obtain optimized forging forming process parameters, multi-objective optimization strategy of process parameters based on response surface method (RSM) was put forward. Taking strain uniformity and forming force of large-scale arc-shaped forging as the evaluation index, the analysis model of combining finite element numerical simulation with response surface method was set up. The degree of fitting of the regression model was up to $87.58 \%$. The optimum combination of process parameters is the flash height of $5.682 \mathrm{~mm}$, forging speed of $7.25 \mathrm{~mm} / \mathrm{s}$ and friction coefficient of 0.21 . Using the optimized process parameters can make grain uniformity improved greatly, and the forging deformation force is effectively reduced.
\end{abstract}

\section{Introduction}

With the progress of science and technology and the development of the aviation industry needs, Aluminum Alloy forging increasingly toward large-scale, overall direction of development. However, large size Aluminum Alloy dieforgings production often exceeded the existing equipment capacity, how to use the existing equipment conditions to produce large size forgings is China's aviation manufacturing faces an important issue ${ }^{[1]}$. Such forging in the forming process prone to forming filling with uneven ${ }^{[2]}$. At the same time, fiber breakage and other defects such forging required relatively ordinary forging forming load is generally much larger, so the research of forging deformation uniformity and forming load is very important.

\section{Forging Process Design}

The large arc shape Aluminum Alloy forgings are important materials for load-bearing components, 7175-T66 Aluminum Alloy, its chemical composition as shown in Table 1. The length of the forging maximum size to the width direction $5500 \mathrm{~mm}$, maximum size is the maximum height of $700 \mathrm{~mm}$ yuan $100 \mathrm{~mm}$ yuan reinforced slab width and height were $70,40 \mathrm{~mm}$, Rutu the 1 is shown in Figure 2 . The scheme for forging preform.

Tab.1 Chemical composition of 7175-T66 aluminu alloy (wt\%)

\begin{tabular}{|c|c|c|c|c|c|c|c|}
\hline $\mathrm{Al}$ & $\mathrm{Cr}$ & $\mathrm{Cu}$ & $\mathrm{Fe}$ & $\mathrm{Mg}$ & $\mathrm{Mn}$ & $\mathrm{Si}$ & $\mathrm{Zn}$ \\
90.34 & 0.22 & 1.84 & 0.16 & 2.60 & 0.08 & 0.12 & 5.7 \\
\hline
\end{tabular}




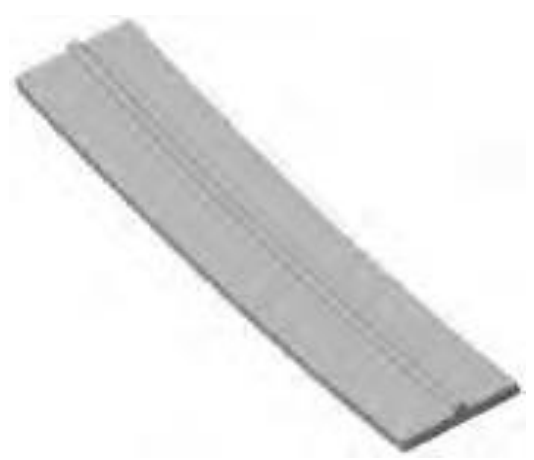

Fig.1 Arc-shaped aluminum alloy forging

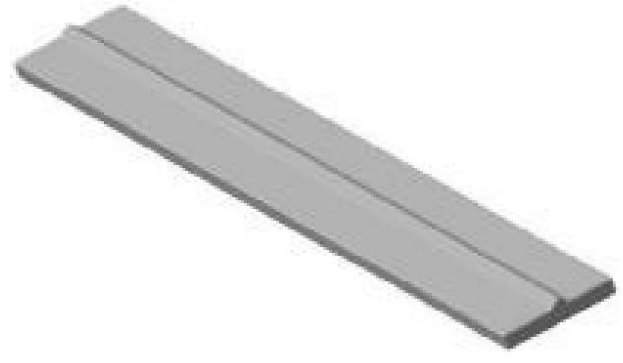

Fig.2 Preform scheme of arc-shaped aluminum alloy forging

\section{Application of Response Surface Methodology to Optimize Process Parameters}

Response surface methodology (RSM) is a combination of mathematical methods and statistical methods. It is used to model and analyze the variables of interest. The response surface method has a significant advantage in dealing with complex optimization problems, such as the extreme difficulty of the design variables and the high degree of nonlinearity. With the improvement of computer performance ${ }^{[3]}$, RSM has been widely used in the field of optimization design, reliability analysis and calculation, dynamics research, engineering process control and so on. The prediction model of response surface method is polynomial model and two order model (formula (1), (2)), and the coefficient of polynomial is determined by regression analysis ${ }^{[4-5]}$.

First-order model: $\mathbf{y}=\beta_{0}+\sum_{i=1}^{k} \beta_{i} x_{i}+\varepsilon$

Two order model: $\mathbf{y}=\beta_{0}+\sum_{i=1}^{k} \beta_{i} x_{i}+\sum_{i=1}^{k} \beta_{i} x_{i}^{2}+\sum_{i\langle j}^{k} \beta_{i j} x_{i} x_{j}+\varepsilon$

Objective Function. In order to optimize the microstructure, it is necessary to quantify the single objective of the qualitative description and to select the appropriate physical quantity to establish the corresponding mathematical model. The evaluation function of the grain uniformity of forging is as follows.

$$
\Psi_{1}=\sqrt{\sum_{\mathrm{i}=1}^{\mathrm{k}}\left(\bar{\varepsilon}_{\mathrm{i}}-\varepsilon_{\text {avg }}\right)^{2}}
$$

Type $\mathrm{n}$ for the simulation of the total number of units; $\bar{\varepsilon}_{\mathrm{i}}$ is average strain for each cell in the simulation; $\varepsilon_{\text {arg }}$ is the mean value of the average strain of the final forging.

Due to the high strength and large volume, the large steel plate forgings are often easy to exceed the equipment condition, so the optimization of the load is also the key to the deformation force function

$$
\Psi_{2}=\frac{1}{n} \sum_{i=1}^{n} \sigma_{i j}
$$




\section{Finite Element Simulation Results Analysis}

Through the process of large forgings Aluminum Alloy analysis, using Deform finite element of different preform proposed simulation software, in the process of two kinds of blank in different forming period of forming load, stress and strain, average grain size and forming uniformity of flash forming focus on forging, analyzes two different the advantages and disadvantages of billets are compared and determined, more ideal preform.

Strain Uniformity Analysis. Figure 3 shows the equivalent strain distribution of preform in forming process of preform 1 . It can be seen from the figure that the plastic deformation of preform 1 is mainly concentrated in the middle part of the billet and the contact part of the mold, and with the formation of the plastic deformation area gradually expanded. The preform in the middle 1 accumulated material more, when formed by squeezing the material a lot of middle to outside the main part of forging forming, therefore the majority after severe deformation, the two corners of the blank forging because the distance is far less central and should be changed, and even the lack of materials. The strain difference of preform 1 during forming process. Figure 4 is the equivalent strain distribution of preform blank in forming process of figure 2 . As is shown in the drawing, the main part of the preform is deformed and the strain is more uniform in the process of forming because of the 2 blank of the preform, so the strain distribution uniformity is improved by the preform forming in 2 .

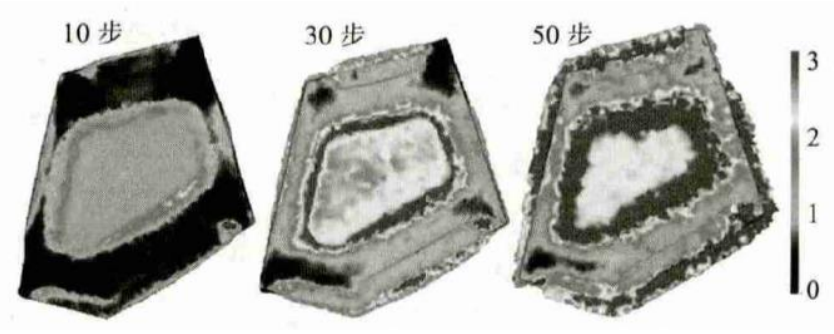

Fig.3 The strain distribution of preformed blank 1 in forming process

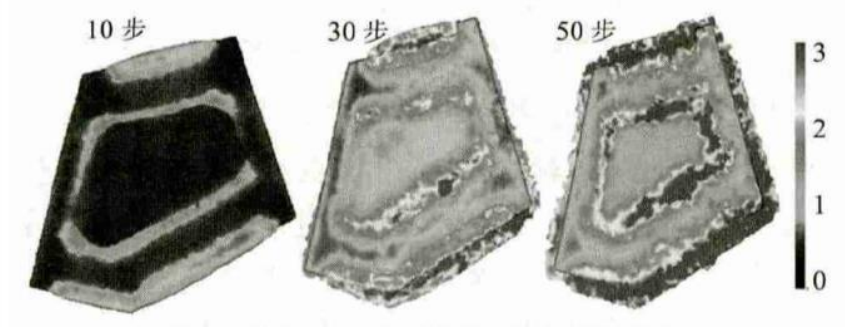

Fig.4 The strain of preformed blank 2 in forming proces

Microstructure Uniformity Analysis. In order to make an accurate analysis of the forging structure of different blank, 3 feature points were selected to study the evolution of the grain size during the forming process. Figure 5 is the distribution of selected feature points. It is located in the main part of the forging, and is also the force part of the forging. Therefore, the grain state of these parts has a great influence on the performance of forgings.

The Distribution of the Flash. The study on the distribution of the preform in different blank forming. 16 points in the outer edge of forging (from the right corner, such as distance distribution) were measured, the fly edge width, so as to measure the blank distribution is reasonable. 


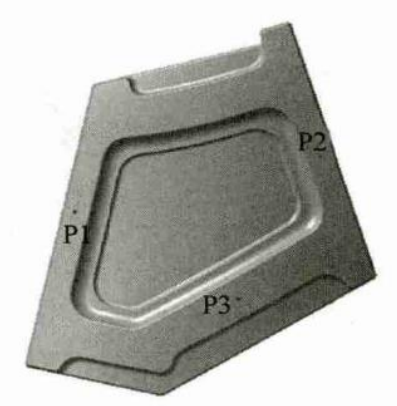

Fig.5 The distribution of forging characteristic points

\section{Conclusion}

Based on the analysis of the characteristics and forming process of the large aluminum alloy forgings, the design of the preform is made, and the forging process is simulated with the finite element software, and the forming of the different preforms is analyzed.

The use of blank 2 forming is beneficial to improve the uniformity of the forming process in the process of uniform flow. The results are verified by experiments.

\section{References}

[1] Timokhiina I B, H0dgson P D, RRinger S. Percipitate charac-terization of advanced high strength low-alloy (HSLA) steel us-ing atom probe tomography [J].Scripta Materialia,2007,56(7): 601-604.

[2] Mondolfo L F. Aluminum alloys structure and properties[J]. Butterworhts, 1976, 48:845-851.

[3] V. V. Zakharov. Effect of Scandium on the Structure and Properties of Aluminum Alloys[J]. Metal Science and Heat Treatment, 2003,45: 246-253.

[4] L. L. Rokhlin, T. V. Dobatkina, I. G. Korol'kova, M. N. Bolotova. A study of the joint effect of scandium and chromium on the structure and mechanical properties of aluminum and its alloys with magnesium[J]. Metal Science and Heat Treatment, 2008, 50(3): 115-119.

[5] Williams B W, Worswick M J, D'Amours G, et al. Influence of forming effects on the axial crush response of hydroformed aluminum alloy tubes[J]. International Journal of Impact Engineering, 2010, 37(10): 1008-1020. 